\title{
Do Poor Students Benefit from China's Merger Program? Transfer Path and Educational Performance
}

\author{
Xinxin Chen, Hongmei Yi, Linxiu Zhang, Di Mo, James Chu, Scott Rozelle
}

\begin{abstract}
Aiming to provide better education facilities and improve the educational attainment of poor rural students, China's government has been merging remote rural primary schools to centralized village, town, or county schools since the late 1990s. To accompany the policy, boarding facilities have been constructed that allow (mandate) primary school-aged children to live at school rather than at home. More generally, there also have been efforts to improve rural schools, especially those in counties and towns. Unfortunately, little empirical work has been available to evaluate the impact of the new merger and investment programs on the educational performance of students. Drawing on a unique dataset that records both the path by which students navigate their primary school years (i.e., which different types of schools did students attend) as well as math test scores in three poverty-stricken counties, we use descriptive statistics and multivariate analysis (both OLS and covariate matching) to analyze the relationship between different transfer paths and student educational performance. This allows us to examine the costs and benefits of the school merger and investment programs. The results of the analysis show that students who attend county schools perform systematically better than those attend village or town schools. However, completing primary school in town schools seems to have no effect on students' academic performance. Surprisingly, starting primary education in a teaching point does not hurt rural students; on the contrary, it increases their test scores in some cases. Finally, in terms of the boarding effect, the neutral estimate in OLS and the negative estimate in covariate matching results confirm that boarding at school does not help the students; in some cases it may even reduce their academic performance.
\end{abstract}

JEL: 124; 128; 018

Keywords: Merger Program; transfer path; educational performance; rural China

Working Paper 231

September 2011

reapchina.org/reap.stanford.edu

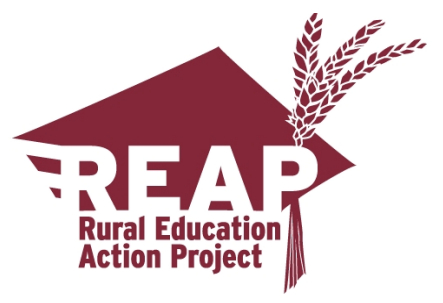




\title{
Do Poor Students Benefit from China's Merger Program? Transfer Path and Educational Performance
}

\author{
Xinxin Chen* \\ Zhejiang Gongshang University \\ Hongmei Yi and Linxiu Zhang \\ Center for Chinese Agricultural Policy, Institute for Geographical Sciences and Natural \\ Resources Research, Chinese Academy of Sciences \\ Di Mo \\ LICOS, K.U.Leuven \\ James Chu and Scott Rozelle \\ Stanford University
}

The authors would like to acknowledge the support of LICOS, K.U.Leuven, a gift from Jade Chien, an alumni of Stanford University, grant from the National Natural Science Foundation of China (70803047) and the Natural Science Foundation of Zhejiang Province (Y607420), and supporter/advisor of the Rural Education Action Project. The project could not have been done without the collaboration of the Ningshan County, Shiquan County and Hanying County bureaus of education. The students from Northwest University of Xi' an carried the burden of the survey work. We thank each and every one of them.

*Corresponding author: Xinxin Chen

Mailing address: Department of Economics, Zhejiang Gongshang University, No. 18, Xuzheng Street, Xiasha University Town, Hangzhou, 310018 China

Tel. 86-571-28008042 Fax: 86-571-28008035

E-mail: chenxx@mail.zjgsu.edu.cn 


\section{Do Poor Students Benefit from China's Merger Program? Transfer Path and Educational Performance}

\section{Introduction}

Aiming to improve the quality of rural education and reduce educational disparities between urban and rural areas, China's State Council implemented the Rural Primary School Merger Program in the late 1990s. Especially during early and mid 2000s, many one-room schoolhouses offering schooling from grades 1 through 4 -so called teaching points (jiaoxuedian)—were shut down and merged into centralized schools in larger villages and towns. Resources were channeled towards larger schools in selected towns and the county seat, and the role of smaller village schools was downgraded. Indeed, the number of primary schools in rural China fell by 50\% between 1999 and 2009 (National Bureau of Statistics, 2000, 2010).

Given the broad scope of the Merger Program (and future plans to continue the Program), a significant question is whether the initiative has had any net benefit for poor children in rural areas. In teaching points a single teacher is responsible for teaching every student in every grade from grade 1 to grade 4 . The teacher typically teaches all students - in grades 1 to 4 -in a single classroom. With insufficient resources, teachers in

\section{Working Paper 231}

\section{September 2011}

reapchina.org/reap.stanford.edu

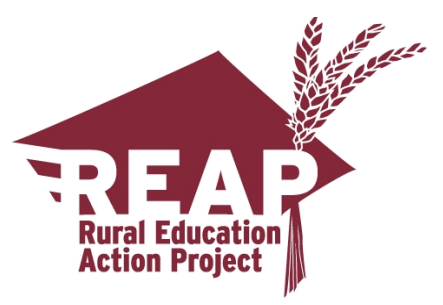


teaching points often only teach math and Chinese and little in the way of other courses (such as, art, science or music). In contrast, centralized town or county schools have specialized teachers, better facilities and more curricular offerings (Zhuo, 2006). If access to these better facilities, teachers and curriculum positively affects the educational performance of children, we can say that there is a positive resource effect.

On the other hand, there are aspects of school mergers that may have a number of adverse effects on students. First, transferring may reduce the student's level of comfort and familiarity (associated with going to school in one's own village — as it typically in a teaching point or a village primary school), thus negatively affecting educational performance. Second, students who transfer to a new school usually live far away and must board at the school. Third, the lack of parental care (because children live away from home) might also lead to psychological problems, especially for young students from grade 1 to grade 3 (Pang, 2006; Luo et al., 2009). Fourth, students who board at centralized schools have been shown to have poorer nutrition and health relative to the students that live at home (Luo et al., 2009; Luo et al., 2010). In turn, poor nutrition and psychological problems almost certainly detract from student learning. We call these adverse effects the disruption effect.

Finding the net benefit of the Merger Program requires an analysis of both its benefits (the resource effects) and costs (the disruption effects). To date, we know of only one research team that has published an empirical paper disaggregating costs and benefits to determine the net effect of the Merger Program on students. Using data from a large sample in Shaanxi province in the early 2000s, Liu et al. (2010) found that the overall 
effect of transferring students from a village school or teaching point closed under the Merger Program to a larger, more central school is neutral; that is, the positive benefits from the improved resource effect were similar in magnitude to the negative costs.

However, specific policies to merge schools differ across provinces, prefectures, and even within counties (Liu et al. 2010). Henan Province merged all village schools into one for each village if the village has a population above a certain threshold. Yunnan Province shut down teaching points with only one teacher and merged them into village schools. Qinghai Province established town and county boarding schools to receive students from nearby villages and teaching points. These are but three province level policies; counties and prefectures also adjusted these policies in practice (Liu et al. 2010). In addition, in our interviews in China's poor northwest region in 2009 and 2010, we often have found that two or more of these different policies and resulting transfer paths can exist in a single county. As such, the Merger Program does not only shift students from teaching points to county schools. In fact, primary school students transfer from school to school in a variety of permutations: teaching point to village school; teaching point to town school; village school to another village school; village school to town school; village or town school to the county seat school; and more. In the rest of the paper we term the different paths taken by different students through primary school transfer paths.

In summary, specific transfer paths can and often differ by student. Moreover, because each transfer path has its own unique set of benefits (resource effects vary across types of schools) and costs (disruption effects also can vary across types of schools), it is 
possible that different transfer paths will have different impacts on the educational performance of students. This fact further complicates the debate about merger costs and benefits and must be addressed to develop a comprehensive argument.

To our knowledge, no published empirical study in development economics exists that evaluates the costs and benefits of the Merger Program while accounting for different transfer paths of students. In the Liu et al. paper (2010), the authors compare students who transfer to schools (guest students) with students who were originally at the school (host students) to examine the effect of mergers. However, they only measure the effect of switching schools due to mergers and do not account for the different kinds of schools that students can transfer out from or transfer into. Certainly a rigorous analysis of the costs and benefits associated with the program could suggest potential adjustments to policymakers. Given the scope of the mergers today (and plans for continue in the future), such a study is overdue.

The overall goal of this paper is to evaluate the effect of different transfer paths on student educational performance. At the broadest level we ask, what are the net benefits related to the different transfer paths for poor, rural students? The key questions we attempt to address in our study include: a.) What transfer paths are students taking as a result of the Merger Program and other educational policy shifts? b.) How are student test scores affected by transfer paths? c.) Are there any negative impacts of the Merger Program? d.) Is educational performance affected by whether or not students live at home or board at school? 
In order to answer these questions, we draw on a dataset we collected in three poverty-stricken counties in China. We begin by categorizing types of transfer paths among students in the sample counties. We then compare standardized math test scores among students that have taken different transfer paths. We also use different estimation strategies - OLS estimation and covariate matching - to examine the impact of transfer paths and boarding statuses of the students on their educational performance. These estimation strategies attempt to control for the fact that both educational performance and transfer paths may be affected by the characteristics of students and their families. Finally, based on the empirical results, we discuss the net potential benefits of the Merger Program and its impact on poor, rural students.

\section{Data Collection}

Our data come from a survey we fielded in three counties (Ningshan, Shiquan and Hanyin) in the south part of Shaanxi Province, one of the nation's poorest provinces. These counties are well-suited to answering our research question. First, these counties were either nationally- or provincially-designated poor counties. ${ }^{\mathrm{i}}$ They thus broadly represent the rural poor in China. Second, county officials launched the Merger Program in these counties at the end of the 1990s, and sufficient time has passed for the policy to take effect. Third, the transfer paths of the students in these sample counties are diverse, such that there is sufficient variation to study the relationship of transfer paths and educational performance. 
Our sample was drawn from 36 junior high schools in the three study counties. In Ningshan County, all the seventh and eighth grade classes in all of the junior high schools were selected. In Shiquan County and Hanyin County, a subset of seventh grade and eighth grade classes in every junior high school were randomly selected. Because of the size of Shiquan and Hanyin, it would have been impossible, given our budget, to survey all classes in each school in these two counties.

In every sample class, we surveyed all the students. The total sample of 5700 students consists of 2798 seventh graders in 2009. The total sample also included 2902 eighth graders.

The sample of students appears to be similar in nature to what would be expected in a rural, poor setting. For example, we find $6 \%$ more boys than girls, a ratio similar to that cited in the Ministry of Education's 2010 Annual Yearbook: 7\% more boys than girls. Approximately $98 \%$ of the seventh graders are aged between 11 and 15 years and about $99 \%$ of the eighth graders are aged between 12 and 16 years.

Our measure of educational performance, the key dependent variable in the study, was based on a 30-minute standardized math test that we administered ourselves. Since the test was administered at the beginning of the school year, the test is measuring the accumulated math ability from each student's elementary schooling for seventh graders and for eighth graders it is, in part, measuring measure the accumulated math ability from students' elementary schooling (but, only in part, since they had already studied in junior high for one year). This math test was scored on a scale from 0 to 100 . The results that we obtain closely approximate a normal distribution with a mean score of 54 points and a 
standard deviation of 17 points for seventh graders and a normal distribution of mean score of 57 points and a standard deviation of 19 points for eighth graders. We keep the scores without any further manipulation (that is, we do not normalize them as is done in some educational studies) for the ease of interpretation.

To measure our main independent variable, the transfer path of each student, we collected detailed information on the schooling histories of each student. We asked students when and where they attended each grade during their primary school years in order to create a variable to characterize each student's transfer path from grade 1 to grade 6. In addition, we also asked questions about school type and boarding status (either living at home or living at school) in each grade. Based on the answers to these questions, we created variables for student transfer path, boarding status and each student's primary school educational experience.

In addition to educational performance and transfer path status, we also collected information on each student's personal and family characteristics to use as controls. Variables included each student's age, gender, household registration status (either urban or rural, also called hukou), and ethnicity; each family member's age, educational attainment, and employment status; the household's land holdings; and the total number of household members. The answers to detailed questions about household assets were used to generate a variable measuring the value of the household durable assets to represent household socioeconomic status or wealth. All of the controls in the study's empirical model are produced from the above information.

\section{Transfer paths and educational performance}


In part because of the closing and/or merging of a large number of rural schools, 2062 of the 5700 students in our sample (nearly 36 percent of our sample) transferred from one school to another at some point during their primary school years. Our data contain many unique starting and ending points for the transfer experiences of students, which we use to identify a variety of student transfer paths. In this section, we provide a general picture of these transfer paths, and describe the relationship between these paths and educational performance.

\section{Student transfer paths}

Our data confirm that there are indeed different transfer paths among the 36 percent of students in our sample that started school in one type of school and finished in another (Table 1). Generally speaking, more students transfer to town and county schools than transfer from them (row 3; row 4). Likewise, more students transfer from teaching points and village schools than transfer to them (row 1; row 2). To be specific, only $28 \%$ of all students started primary education in town schools, but 45 percent of students finished primary education in town schools. At the same time, the percentage (41\%) of the students who finished primary education in village schools is less than the percentage $(44 \%)$ of the students who finished primary education in village schools. Furthermore, the percentage (14\%) of students who finished in county schools is a little more than the percentage $(10 \%)$ of students who started primary education in county schools. These patterns suggest that, in our sample, students are being encouraged to transfer from teaching points or village schools to more centralized town and county schools. Moreover, town schools are the main destination schools for rural students. 
There are some types of schools that play specific roles in different transfer paths. Among the students that started primary education in teaching points (18\% of all students), none of them transferred to a teaching point (row 1). The fact that no student finished primary education in a teaching point reflects the fact that teaching points, by definition, do not provide education beyond the fourth grade. Moreover, no student transferred from one teaching point in his/her village to a teaching point in another village. Again, this finding reflects the fact that teaching points are designed to allow younger students to go to school in his/her own village under the tutelage of a teacher that can get to know the students.

Our data also show that transfer paths differ substantially even among students who start primary education in the same type of school (Table 2). For example, around 63 percent $(655 /(316+655+68))$ of students that started in teaching points eventually transferred to town schools. Another 30 percent $(316 /(316+655+68))$ transferred to village schools. The remaining 7 percent $(68 /(316+655+68))$ of students that started in teaching points transferred to county schools. As such, our data shows that students from teaching points were transferring to more centralized but different kinds of schools.

The same is true for students who started their primary school years in village schools (Table 2). Of the 761 students $(417+98+246)$ that started in village schools, $55 \%$ (417 of them) transferred to town schools (column 1, rows 4 to 6 ) and 13\% (98 of them) transferred to county schools. The remaining 32\% (246 of them) transferred to another village school. This movement further reveals that, in our sample, more students transferred to town schools than village/county schools under the Merger Program. 
Taken together, the data show that few students transferred from town schools to village schools (or other combination of "reverse flows"). Only 48 students transferred from a town school to a village school (Table 2, row 7). Even fewer $(26=11+15)$ transferred from a county school to either a town or village school (rows 10 and 11).

Finally, a subset of students transferred between schools, but stayed in the same administrative level. For example, there were some students (82) that transferred between town schools (from town to town-row 8). There were 20 students in our sample that transferred between county schools (county to county-row 12).

\section{Educational performance across transfer paths}

We now turn to consider how various student transfer paths are correlated with the mean math scores, which are used as proxies for educational performance (Table 2). This analysis helps us identify and isolate several of the effects associated with different transfer paths.

First, it appears that the higher level the school (village versus town versus county), the higher the test scores. According to our data, among students who did not switch schools, students in county schools score higher than students in town or village schools To be specific, the test scores of students that spent all six years of primary school in the same county school (66.0 - row 15) are greater than students that stayed in the same town school (52.1 -row 14). The scores of students that stayed in the same town school for all six years, in turn, are higher than students that spent all six years in the same village school (51.7-row 13). Likewise, when comparing students that transferred from one school to another within the same level of schooling (that is: county to county; town 
to town; or village to village- rows 4, 8 and 12), scores are higher in the case of county schools (72.3) relative to those in town (55.4) and village schools (51.0). From these numbers it would appear that the Merger Program, to the extent that schooling is being concentrated in towns and counties, is benefitting rural students.

The propensity to score higher on the standardized test of the schools in the county seat can also be seen in our data. The scores of students who either spent all six years in county schools (transferring from county to county or staying in the same county school — rows 12 and 15) or finished their primary school years in a county school (teaching point-county; village-county; town county_rows 3, 6 and 9) all exceed 63 points. When students did not attend a county school (with the rare exception of the few students that started in county schools and finished in either a village or town school—rows 10 and 11), the scores are all 59 points or less. The mean scores of students that attended county schools (rows 3, 6, 9, 12 and 15) are 66.2 points; the mean scores of students that did not attend county schools (rows $1,2,4,5,7,8,13,14$ ) are 53.3 points. Taken together, this evidence suggests that county schools foster the best academic performance among all types of schools.

Furthermore, using the same data, but examining different combinations of transfer paths, the disruption effect of switching schools (that is, holding the level of schooling constant) is not particularly evident. Specifically, when we compare the scores of students that transferred from one county school to another county school, their scores are higher (72.3 - row 12) than students that stayed in county schools for all six years of primary school (66.0 - row 15). The town-town transferees also scored higher (55.4-row 
8) than students that stayed in one town school for all six years (53.1—row 14). The scores of village-village transferees are almost identical to scores of students who stay in the same village school (51.7 versus 51.0-rows 4 and 13). From this descriptive analysis there is even more support for the efficacy of the Merger Program; there are no empirical grounds in our sample that suggests the disruption effect is serious. ${ }^{\text {ii }}$

However, somewhat surprisingly, the descriptive data in Table 2 may point to a weakness in the Merger Program. One of the main targets of the Merger Program is to shut down teaching points, but students may benefit when they start their primary schooling in teaching points versus other types of schools. In the case of transfers from teaching points to village schools (row 1), the scores of the students (56.2) are higher than when students are either in the village to village (51.0) or village only (51.7) transfer paths (rows 4 and 13). In the case of transfers from teaching points to town schools (row 2), the scores of the students (58.7) also are higher than when students are in the town to town (55.4) or town only (52.1) transfer paths (rows 8 and 14). One interpretation of these comparisons is that, in fact, there may be some benefit to having young children (less than fourth grade) stay in their own village to go to school, rather than attending a school outside of the familiar environment of one's own home community. It could also be that the attention/care paid to students in a teaching point up to grade 4 is able to offset lower quality in teaching ability and/or less broad course offerings. Our study, of course, can never tell us why. However, this evidence raises the hypothesis that teaching points have strengths, and those strengths might need to be preserved in teaching points or replicated in larger, centralized schools. 


\section{Boarding or living at home}

One of the key components of China's Merger Program is to allow students to board at school as a way to enjoy the positive benefits of greater resources in centralized schools. However, it is possible that living and taking meals away from home is one of the large parts of the cost associated with the disruption effect. Luo et al. (2009) have documented the deficient nature of boarding facilities. Luo et al. (2010) shows that students in boarding facilities are less well nourished and have lower scores on standardized tests. Because of this fact, it is important to try to isolate the boarding effect, given equal levels of the resource effect.

We can begin isolating the boarding effect by comparing the scores of boarding and non-boarding students that went through the same transfer path. When looking at the data in this way, we can see that 10 of the 15 different transfer paths can be used to make comparisons. Observations on five of the transfer paths (teaching point-county; village-county; town-county; county-county; and in the same county-only) could not be used since none of these students in the transfer path live at school (because in our three sample counties, there were no boarding facilities in the county seat schools). Among the other 10 transfer paths (those that involved schools in villages and towns and not schools in the county seat), some students boarded whereas others lived at home.

Using this subset of data, descriptive statistics provide a mixed picture of the relationship between boarding ${ }^{\mathrm{iii}}$ and test scores (Table 3). There are six transfer paths (teaching point-village school; teaching point-town school; village-village school; village-town school; county to village school; and in the same town school only) in which 
the scores of boarding school students are higher than the non-boarding school students (rows 1, 2, 4, 5, 10 and 14). In the other four transfer paths (town-village school; town-town school; county-town school; in the same village school-only) the scores of the non-boarding students are higher than the boarding students (rows 7, 8, 11 and 13). Since there are more observations in the subset of six transfer paths in which the boarding school students outperform the non-boarding school students, one might be inclined to suggest that there is no detrimental effect to living at school.

When looking at the entire sample, however, a different story emerges (Table 3, row 16). Out of the total number of students in our dataset (5546), 34 percent of them (or 1871 students) boarded at school in the year that they were finishing their primary school (that is, typically during grade 6). The other 66 percent (or 3675 students) lived at home during their sixth year in primary school. When comparing these two groups, the scores of the non-boarders (56.0) are greater than the scores of the boarders (54.2). Hence, given the mixed nature of the results using descriptive statistics, it is important to examine the results from a multivariate analysis.

\section{Other effects and descriptive analysis summary}

The educational performance of the students might also be affected by other characteristics in addition to the transfer paths and boarding status. According to the literature (Liu et al 2010, Chen et al, 2009, Linnemayr et al, 2008, Shariff, 1998, etc.) individual student characteristics, such as gender, age, hukou identity, pre-school experience and number of siblings may also affect educational performance. Parental characteristics, like age, education and occupation; and household characteristics like 
household size and wealth also have been shown to affect educational performance. These findings underline the importance of conducting multivariate analysis and including parental and household characteristics in the analysis as control variables, since they may also be correlated with student transfer paths.

In summary, then, most of the descriptive analysis appears to support the need to put more resources into schools, as has been done into the town and county schools. In most cases, students that have gone to schools in the higher levels of schooling have higher scores. Furthermore, transferring per se also does not have any obvious, large disruption effects. Hence, the resource effect seems to dominate. The one (potentially important) exception is that the quality of schooling in teaching points in our sample counties may not be so bad that teaching points should be shut down at any cost. In fact, students that attended teaching points as part of their transfer paths often performed better in terms of test scores than many of their counterparts. Overall, boarding appears to reduce educational performance, but there are many transfer paths in which the boarding effect is positive. Such findings in the descriptive statistics provide a rich empirical basis for proceeding with the multivariate analysis in the rest of the paper.

\section{Econometric Estimation Strategy}

In this section we describe the estimation strategy for the econometric analysis (which will be used to further examine the impact of student transfer paths on academic performance). In the first subsection we present different estimators and specifications. In 
the second subsection we discuss how we intend to perform robustness and sensitivity checks.

\section{Basic estimator-Ordinary Least Squares (OLS)}

In order to estimate the impact of student transfer paths and boarding status on math test scores, we use OLS controlling (at least in part) for selection bias and endogeneity due to unobserved heterogeneity. We do so by including a set of observable covariates in the regression of key independent variables on math scores:

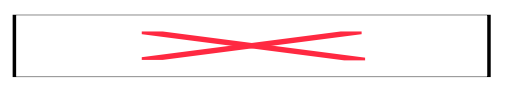

where the dependent variable $Y_{i}$ indicates the math score of student $i$; $P_{i}$ is a vector of our variables of interest that includes fourteen student transfer path dummy variables. The variables are the transfer paths that include students transferring: a.) from a teaching point school to a village school; b.) from teaching point school to a town school; c.) from a teaching point school to a county school; d.) from a village school to another village school; e.) from a village school to a town school; f.) from a village school to a county school; g.) from a town school to a village school; h.) from a town school to another town school; i.) from a town school to a county school; j.) from a county school to a village school; k.) from a county school to a town school; 1.) from a county school to another county school; m.) stay in the same town school and n.) stay in the same county school. The vector of parameters, $\beta^{\prime}$, contains measures of the effects of the transfer path that we are interested in. The comparison group in this specification includes the students that studied in the same village school for all six years of primary school. 
In the rest of the equation, the symbol, $B_{i}$, the boarding status indicator variable, is also one of the other variables of interest. In equation $(1), B_{i}$ is a dummy variable which equals 1 if the student boarded at the school where he/she finished primary education and 0 if he/she did not board. Finally, the term, $X_{i}$ is a vector of covariates included to capture the effect of the characteristics of the student, his/her parents, and household on the dependent variable (see discussion in the previous paragraph).

Analyzed in this way, we will be able to test more rigorously some of the observations that were made in the descriptive analysis. Specifically, we can see, ceteris paribus, if math scores of students in county schools are systematically higher than the scores of students in town and village schools. The model can be used to assess the relative performance of students that transferred compared to those that did not transfer (all other things being equal). Additional tests can be carried out to measure the differences in scores of students that attended teaching points and those that did not. Finally, holding the nature of the transfer path constant, we will also be able to examine if living at school or home is associated with higher test scores.

\section{Alternative Estimation Approach-----Covariate matching}

In place of controlling for the covariates by adding additional regressors as we do in the OLS regression (described in the section immediately above), we can also use covariate matching as an alternative method to estimate the effect of transfer path on student educational performance. The main idea behind covariate matching is to select a treatment group and comparison or control group with identical observables, $X$, and compare the outcomes of these two sets of groups (Rubin, 1974). Given a certain set of 
assumptions, covariate matching helps to correct the bias in estimation due to observables, because the source of the bias is the difference of observables in the treated group and comparison group. Matching on covariates by definition will remove this difference and hence the bias (Zhao, 2004).

One of the main advantages of covariate matching over regression adjustment is that this method highlights areas of the covariate distribution where there is insufficient overlap between the treatment and control groups, such that the resulting treatment effect estimates would rely heavily on extrapolation (Stuart, 2010). Regression models have been shown to perform poorly when there is insufficient overlap, but their standard diagnostics do not involve checking this overlap (Dehejia and Wahba, 1999; Glazerman et al., 2003). Another advantage of covariate matching is that it does not require assumptions about linearity or constant treatment effects, and thus improves bias correction (Zhao, 2004). Studies have shown that methods such as linear regression adjustment can actually increase bias in the estimated treatment effect when the true relationship between the covariate and outcome is even moderately non-linear. Linear regression can increase bias especially when there are large differences in the means and variances of the covariates in the treated and control groups (Rubin, 1974; Heckman et al., 1998). Thus, covariate matching is becoming a more general method than standard linear regression. In our setup, the treatments are defined to be the different student transfer paths and boarding statuses and we can use matching to examine the difference in test scores among students that are in different subsets of transfer paths. 
In sum, we are ultimately interested in estimating the average treatment effects on the treated (ATT) - measured in test score differences — of attending a county school (versus not attending county schools); of transferring to a new school (versus staying within the same school); of starting primary education in a teaching point school (versus not starting in a teaching point); and of living at school as a boarder (versus living at home).

\section{Econometric Results}

The estimation results of the basic estimator (OLS) using equation (1) are presented in Table 4. Columns (1) to (2) of Table 4 differ in the independent variables that are included in estimation: column (1) only includes the student transfer path variables (with no covariates); in column (2) we include the boarding status variable and all of the covariates. In addition, columns (3) and (4) are almost the same with column (2) except that a different comparison group of transfer path dummy variables are used in order to get the disruption effect of switching schools directly. That is, in column (2), the comparison group consists of students who studied in the same village school throughout primary school. The comparison group in model (3) consists of students that spent all six years in the same town school, and the comparison group in model (4) consists of students who stayed in the same county school for all six years. The model performs better as we move from column (1) to columns (2)/(3)/(4) as the R-square grows and covariates are shown to effectively capture more of the variation in math scores. Therefore, in the rest of our discussion we mostly focus on the results in columns $(2) /(3) /(4)$.

Based on Table 4, there are four main results. First, consistent with the descriptive analysis, the higher level the school the higher the test scores of students. Our results 
show that math scores of students in county schools are systematically higher than scores of students in town or village schools. Among students that never transferred to a new school throughout primary education, students who stay in the same county school perform better than students who stay in the same town or village schools. To be specific, everything else held constant, a student who stayed in the same county school scores 9.4 (column 2, row 15) and 11.2 points (column 3, row 15) higher than his or her peers who spent all six years in the village or town school, respectively.

Likewise, among students that transferred to a new school, students who transferred to county schools perform better than those who started in the same school and later transferred to village or town schools, regardless of whether students started primary education in village or town schools. Specifically, among students who started primary education in village schools, students who later transferred to county schools score 9.0 points (8.5-(-0.5), column 2, row 6 and 4$)$ and 7.8 points $(8.5-0.8$, column 2 , row 6 and 5) higher than students who transferred to village or town schools. ${ }^{\text {iv }}$ This is almost the same case for students who started primary education in village or town schools (rows 8 and 9). In short, students attending county schools perform better than students attending village or town schools. These findings may be interpreted as the positive resource effect in county schools: better teachers and higher quality facilities. ${ }^{\mathrm{vi}}$

However, although town schools are the main destination schools to which students transferred under the Merger Program, our results show that attending town primary school seems to have no positive effect on students' academic performance. Specifically, among students who spend all six years of primary education in a same school, students who study in town schools for all six years score 1.8 points lower than students studying in village schools (column 2, row 14). Among students that started primary education in village schools and later transferred to another school, students that 
finished in a town school score 1.3 points higher $(0.8-(-0.5)$, column 2 , row 4 and row 5) than those who finished in another village school. However, the joint test of the coefficients of village-village school transfer and village-town school transfer are not significantly different from zero. These findings suggest that students who transferred to town schools actually do not benefit from the Merger program in terms of the test score and are consistent with Liu et al. (2010).

Second, our OLS results show that the disruption effect of switching schools on students' educational performance is neutral. That is, according to our results, the coefficient of the dummy variable of transfers from village schools to another village school is negative but statistically insignificant $(-0.533$ - column 2, row 4). Compared with students who studied in the same village school for all six years, students who transferred from village schools to other village schools score almost the same. When we further look at the pure impact of transferring to another town school, the coefficient of the town-town school transfer dummy variable is positive but also statistically insignificant (1.379 — column 3, row 8). The result also holds when we compare the scores of students who transferred from a county school to another county school with the scores of students who stayed in the same county school throughout their primary education (column 4, row 12). In short, there is no evidence showing that there is a serious disruption effect of transferring to a new school on poor rural primary students in terms of math test scores. This result holds regardless of whether students transfer to another village, town or county school.

Third, although teaching points have long been considered to have the least resources available, students who started primary education in teaching points perform better than those who started primary education in village or town schools. That is, among students that transfer to village schools, students who start primary education in teaching 
points score 2.8 points higher than those who started primary education in village schools (2.3-(-0.5) — column 2, row 1 and 4). ${ }^{\text {vii }}$ Likewise, other things being equal, compared to students on the town-town school transfer path, students who transfer from teaching points to town schools score 3.5 points higher (3.1-(-0.4) - column 2, row 2 and 8$)$. ${ }^{\text {vii }}$

As such, students who transferred from teaching points seem to benefit from their experience. A number of reasons may explain this finding. First, students in the teaching points live close to home and are thus familiar with the surroundings, spend less time going to and back from the school, and receive more care from their family. Second, students in the teaching points are in a much smaller class than that in more centralized schools. On average, in Ningshan county, there are only 3 students per class in teaching points, but there are more than 12,16 and 18 students in village, town, and county schools respectively (Ningshan Education Bureau, 2010). Small class sizes may mean that students in teaching points receive more care from the teachers. Especially because younger students may need more attention than older students, the benefits of starting in teaching points might offset and even outweigh the disadvantages of the lower quality of teachers in teaching points. Finally, the quality gap in our sample counties between teachers in teaching points and other schools have narrowed substantially since 2000 . In 2000, a number of teachers were fired after failing some teaching examinations (Wang, 2008). Since most of the sample students started their primary education in teaching points in 2001 and 2002, they benefitted from this measure. In addition, before 2000, the teachers from the teaching points often attended special training courses. For example, during 1998 and 2000, every summer teachers from the teaching points received training on teaching method for about a week in Ningshan County (Ningshan Education Bureau, 2010). Thus, in terms of teacher quality, the gap between teaching point schools and village or town schools may have narrowed in recent years. 
Fourth, our results reveal that the effect of boarding is neutral on student educational performance (table 4). Holding other factors constant, the effect of boarding at school is negative but statistically insignificant (row 16). Some reasons suggest why the neutral effect of boarding status might be true. Although the main disadvantage of boarding at school is poorer nutrition and health in boarding schools (relative to the home environment) and less care from parents (Luo et al., 2009), parents are migrating from rural areas. As such, children who live at home may be receiving minimal care anyway. Thus, compared to students who live at home, the cost of boarding at school in terms of reduced parent care might not be high.

In sum, our results from basic estimation show that although transfer per se does not have a serious effect on student educational performance, transferring to county schools systematically benefits rural students in terms of test scores. Second, transferring to town schools seems not to have any positive effects on student educational performance as the Merger Program expected. Third, studying in teaching points through grade 1 to 4 does seem to improve rural students' educational performance. Fourth, there is no evidence in our analysis that boarding at school improves student educational performance. Finally, our covariates affect student educational performance as expected.

\section{Covariate Matching}

Importantly (since they show our results are robust), the results of covariate matching analysis are similar to the OLS results (Table 5). First, consistent with OLS results, the covariate matching results reveal the dominance of county schools. Compared to students who remain in their village or town schools throughout primary education, students who study in the same county school for all six years or transfer from village to county schools score 14.6 points and 7.6 points higher, respectively (Panel A, column 1 and 2). Village school students that transfer to a county school score 11.8 points higher 
than village school students that transfer to another village school (Panel A, column 3).

Likewise, town school students that transferred to a county school score 9.0 points higher than town school students that transferred to another town school (Panel A, column 4). As such, the resource effect in county schools is positive.

However, as found in the OLS analysis, the resource effect in town schools is not evident. Students that spent all six years in town schools scored 1.7 points lower than students that spent all six years in village schools (Panel B, column 1). Although students transferring from village to town schools score 1.5 points higher than students taking village-village school transfer path, the coefficient is not statistically significant (Panel B, column 2). That is, students attending town schools do not appear to benefit from the resource effect compared to students attending village schools.

Second, the result from covariate matching also reveals that the effect of transferring among schools of the same type is neutral. That is, compared to students that study in the same village, town, or county school throughout primary education, students who transfer to a new village, town, or county school at the same administrative level perform about the same (Panel C, columns 1, 2, and 3).

Third, the covariate matching results reveals that starting primary education from a teaching point positively affects student educational performance, regardless when the student later transferred to a village or town school (Panel D, columns 1 and 2). In the case of students who transfer to a town school, students who start primary education in a teaching point score 5.6 points higher than students who start primary education in a town school. The coefficient is statistically significant (Panel D, column 2).

Fourth and finally, our results show that boarding at school does not help student educational performance. Departing slightly from OLS findings, covariate matching results show that on average, students boarding at school score 2.1 points lower than 
students who lived at home. This result is statistically significant (Panel E, column 1). Among students staying in their village schools for six years, students boarding at school score much lower (3.3 points) than students living at home. This result is significant as well (Panel E, column 2). In addition, among students staying in town schools for six years, students boarding at school score 0.55 points lower than students living at home. However, this result is insignificant (Panel E, column 2). Taken together, these findings suggest that boarding does not help student improve their educational performance. In some cases boarding clearly reduces students' academic performance.

\section{Discussion and conclusions}

In this paper we have attempted to understand whether poor students in rural China have benefitted from the Merger Program by analyzing a set of transfer paths that students have taken during their primary education. Despite controversies about the benefits and costs of the Merger Program, our results show that students who attend county schools perform systematically better than those attend village or town schools. However, completing primary school in town schools seems to have no effect on students' academic performance. Surprisingly, starting primary education in a teaching point does not hurt the rural students; on the contrary, it increases their test scores in some cases. Finally, in terms of the boarding effect, the neutral estimate in OLS and the negative estimate in covariate matching results confirm that boarding at school does not help the students; in some cases it may even reduce their academic performance.

Although there may be good reasons (fiscally or pedagogically) for the changes (mergers/building up centralized county schools), our results imply that poor students are being systematically hurt by the rural China's educational system reforms. First, we find that county schools foster the best academic performance among all the schools in rural 
areas. However, there are no boarding facilities in these county primary schools, so poor students have no real way of attending. If they want to attend, families must rent rooms; students' guardians may have to quit their jobs and live with them. These arrangements are usually too costly for poor households, who thus opt to send their children to town or village schools. However, the effect of completing primary education in town or village schools is neutral. That is, students do not benefit from transferring to such schools. Furthermore, although rural poor students do well when starting in teaching points, these teaching points are being shut down. The students in the teaching points leave their familiar circumstances and most of them now study in village or town schools further away. Finally, for poor rural students, village and town schools are mostly far from home and they have to board at school. However, our results show that boarding does not help the poor rural students.

In terms of policy, our paper has several implications. First, the results confirm that transferring to the county schools helps poor, rural students. However, these are largely unavailable to poor students. Policies that improve access to county schools (or schools with resources similar to county schools) might improve the education quality for poor rural students. Second, it seems that the positive resource effect that the government was hoping to achieve by the Merger Program does not apply to most rural students, who are transferring to village or town schools. If the government continues merging village schools (including teaching points) to town schools, it should invest more in town schools to increase the teaching quality (and facilities) in these schools. Third, village schools like teaching points may have redeeming qualities and should not be closed without further investigation of their benefits. Finally, boarding at school does not help poor rural students; if a way could be made to address the negative effects associated with 
boarding — poor nutrition, lack of familiarity, and less personal care—students might benefit from increased access to learning resources and facilities. 


\section{References}

Chen X., Huang, Q., Rozelle, S., Zhang, L., Shi, Y., 2009. Effect of Migration on Children's Educational Performance in Rural China. Comparative Economic Studies 51, 323-343.

Dehejia, R. H. and Wahba, S., 1999. Causal effects in nonexperimental studies: Re-evaluating the evaluation of training programs. Journal of the American Statistical Association 94, 1053-62.

Glazerman, S., Levy, D. M., and Myers, D., 2003. Nonexperimental versus experimental estimates of earnings impacts. The Annals of the American Academy of Political and Social Science 589, 63-93.

Heckman, J., Ichimura H. and Todd P. E., 1998. Matching as an Econometric Evaluation Estimator. Review of Economic Studies 65, 261-294.

Linnemayr, S., Alderman, H., Ka, A., 2008. Determinants of malnutrition in Senegal: Individual, household, community variables, and their interaction. Economics and Human Biology, 6 , 252-263.

Liu, C., Zhang, L., Luo, R., Rozelle, S., and Loyalka, P., 2010. The Effect of Primary School Mergers on Academic Performance of Students in Rural China. International Journal of Educational Development 30 (6), 570-585.

Luo, R., Shi Y., Zhang L., Liu C., Rozelle S., Sharbono B., 2009. Malnutrition in China's Rural Boarding Schools: the Case of Primary Schools in Shaanxi Province. Asia Pacific Journal of Education 29 (4), 481-501.

Luo, R., Zhang, L., Liu, C., Rozelle, S., Sharbono, B., Adams, J., 2010. Behind Before They Start: The Challenge of Early Childhood Education in Rural China. REAP working paper No. 209, CCAP, Beijing, China.

National Bureau of Statistics, 2000. China Statistics Yearbook. Beijing: China statistics press.

National Bureau of Statistics, 2010. China Statistics Yearbook. Beijing: China statistics press.

Ningshan Education Bureau, 2010.The Annual statistics report on education. Report, Ningshan

Pang, L., 2006. Primary and High School Consolidation in Rural China: Issues, Reasons, and Solutions. Education Development Research, 2, 1-6.

Rubin, D. B., 1974. Estimating Causal Effects of Treatments in Randomized and Nonrandomized Studies. Journal of Educational Psychology 66 (1974), 688-701.

Shariff, A., 1998.Women's status and child health. In: Krishnaraj, M., Sudarshan, R.M., Shariff, A. (Eds.), Gender, Population and Development. Oxford University Press, New Delhi, 185-219.

Shi, R., 2004. Experience Drawn from Research on School Consolidation in Foreign Countries. Comparative Education Research, 12.

Shi, Y., Zhang, L., Liu C., Li, H., Rozelle, S., Sharbono, B., 2009. Community Service, Social Responsibility and Educational Performance in Rural China's Middle Schools: Evidence from a Case Study of Northwest China. REAP Working Paper No. 208, CCAP, Beijing, China.

Stuart, E.A., 2010. Matching Methods for Causal Inference: A review and a look forward. 
Statistical Science 25(1): 1-21

Wang Y., 2008, Current Composition of Teachers in Primary and Junior High Schools in Ningshan and Policy Implications, http://rd.ankang.gov.cn/Article/Class11/200801/776.html

Zhao, Z., 2004, Using matching to estimate treatment effects: Data requirements, matching metrics, and monte carlo evidence. Review of Economics and Statistics 86(1): 91-107

Zhuo, M., 2006. Primary School Consolidation in Rural China: Advantages, Disadvantages and Solutions. Education Forum, the Education Department of Fujian Province. 
Table 1. Distribution of sample students by the type of school in which they started primary school and by the type of school in which they finished primary school, in three study counties in Northwest China, 2009

\begin{tabular}{|c|c|c|c|c|c|}
\hline & \multirow{3}{*}{ Type of school } & \multicolumn{2}{|c|}{ Starting school $^{\mathrm{a}}$} & \multicolumn{2}{|c|}{ Ending school ${ }^{\mathrm{b}}$} \\
\hline & & No. & $\%$ & No. & $\%$ \\
\hline & & (1) & $(2)$ & (3) & (4) \\
\hline 1 & Teaching point schools & 1,039 & 18 & & \\
\hline 2 & Village schools & 2,480 & 44 & 2,340 & 41 \\
\hline 3 & Town schools & 1,587 & 28 & 2,544 & 45 \\
\hline 4 & County schools & 594 & 10 & 816 & 14 \\
\hline 5 & Total & 5,700 & 100 & 5,700 & 100 \\
\hline
\end{tabular}

Note: a. Starting school means the school where the students started primary school.

b. Ending school means the school where the students finished primary school. 
Table 2 The math scores of sample students by the transfer path that the students took during their primary school years in three study counties in China, 2009.

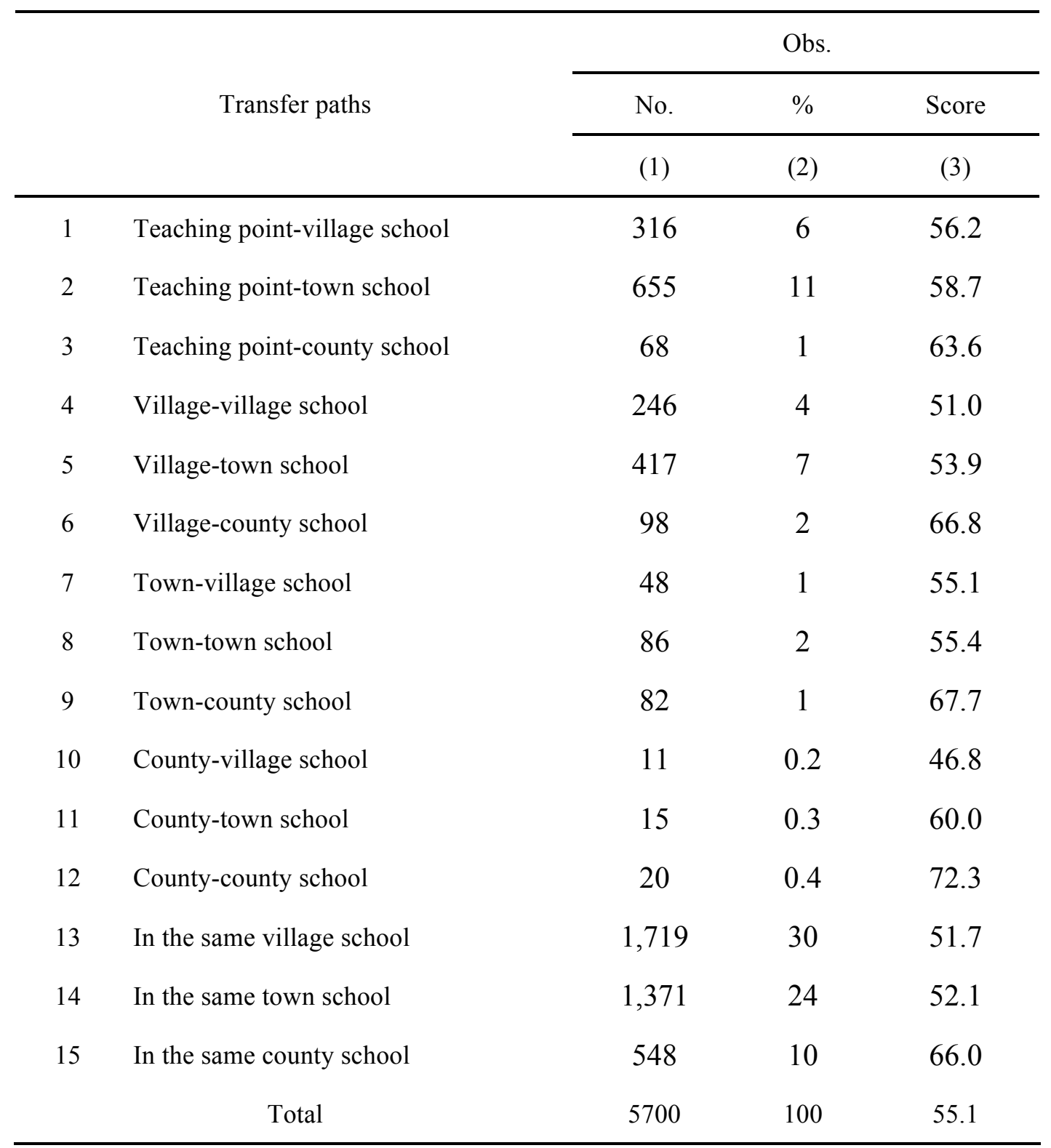

Data source: Authors' survey 
Table 3. The math scores of sample students that live at home and in boarding schools by the transfer path that the students took during their primary school years in three study counties in China, 2009.

\begin{tabular}{|c|c|c|c|c|c|c|c|}
\hline & \multirow[t]{2}{*}{ Transfer paths } & \multicolumn{3}{|c|}{ Boarding ${ }^{\text {a }}$} & \multicolumn{3}{|c|}{ Non-boarding } \\
\hline & & No. & $\%$ & Score & No. & $\%$ & Score \\
\hline & & $(1)$ & $(2)$ & (3) & (4) & $(5)$ & $(6)$ \\
\hline 1. & Teaching point-village school & 163 & 8.5 & 57.9 & 145 & 4.0 & 54.9 \\
\hline 2. & Teaching point-town school & 471 & 24.6 & 59.8 & 169 & 4.6 & 56.5 \\
\hline 3. & Teaching point-county school & 0 & & & 45 & 1.2 & 62.1 \\
\hline 4. & Village (home) -village (away) school & 46 & 2.4 & 53.9 & 180 & 4.9 & 50.7 \\
\hline 5. & Village-town school & 191 & 10.0 & 55.0 & 201 & 5.5 & 53.2 \\
\hline 6. & Village-county school & 0 & & & 91 & 2.5 & 66.5 \\
\hline 7. & Town-village school & 11 & 0.6 & 49.1 & 37 & 1.0 & 56.5 \\
\hline 8. & Town(home) -town (away) school & 29 & 1.5 & 53.6 & 50 & 1.4 & 57.5 \\
\hline 9. & Town-county school & 0 & & & 72 & 2.0 & 68.1 \\
\hline 10. & County-village school & 2 & 0.1 & 50.0 & 9 & 0.2 & 46.1 \\
\hline 11. & County-town school & 7 & 0.4 & 57.14 & 8 & 0.2 & 62.5 \\
\hline 12. & County (home)-county (away) school & 0 & & & 16 & 0.4 & 75.0 \\
\hline 13 & In the same village school & 472 & 24.7 & 51.2 & 1,235 & 33.6 & 51.9 \\
\hline 14 & In the same town school & 479 & 25.0 & 52.7 & 885 & 24.1 & 51.8 \\
\hline 15 & In the same county school & 0 & & & 532 & 14.5 & 66.2 \\
\hline 16 & Total & 1,871 & 100 & 54.24 & 3,675 & 100 & 56.0 \\
\hline
\end{tabular}

Data source: Authors' survey

Note: a. The boarding dummy variable equals to 1 if the student boarded at the school where he/she finished primary education, otherwise it equals to 0 . 
Table 4. Multivariate regression results analyzing the effect of transfer path on the educational performance of all the sample students in three study counties in China, $2009^{\text {a }}$

\begin{tabular}{|c|c|c|c|c|}
\hline \multicolumn{5}{|c|}{ Dependent variable: standardized math score (0-100 points) } \\
\hline Transfer path Dummy Variable & $(1)^{b}$ & $(2)^{b}$ & $(3)^{\mathrm{c}}$ & $(4)^{d}$ \\
\hline \multirow{2}{*}{$\begin{array}{l}\text { 1. Transfer from teaching point to } \\
\text { village school, } 1=\text { yes }\end{array}$} & 4.591 & 2.325 & 4.078 & -7.116 \\
\hline & $(4.46)^{* * *}$ & $(2.26)^{* *}$ & $(3.90)^{* * *}$ & $(4.91)^{* * *}$ \\
\hline \multirow{2}{*}{$\begin{array}{l}\text { 2. Transfer from teaching point to town } \\
\text { school, } 1=\text { yes }\end{array}$} & 7.063 & 3.061 & 4.814 & -6.381 \\
\hline & $(9.13)^{* * *}$ & $(3.58)^{* * *}$ & $(5.64)^{* * *}$ & $(4.89)^{* * *}$ \\
\hline \multirow{2}{*}{$\begin{array}{l}\text { 3. Transfer from teaching point to } \\
\text { county school, } 1=\text { yes }\end{array}$} & 11.948 & 5.836 & 7.588 & -3.606 \\
\hline & $(5.73)^{* * *}$ & $(2.77)^{* * *}$ & $(3.62)^{* * *}$ & $(1.60)$ \\
\hline \multirow{2}{*}{$\begin{array}{l}\text { 4. Transfer from village school to village } \\
\text { school, } 1=\text { yes }\end{array}$} & -0.679 & -0.533 & 1.219 & -9.975 \\
\hline & $(0.59)$ & $(0.40)$ & $(0.89)$ & $(5.90)^{* * *}$ \\
\hline \multirow{2}{*}{$\begin{array}{l}\text { 5. Transfer from village school to town } \\
\text { school, } 1=\text { yes }\end{array}$} & 2.263 & 0.776 & 2.528 & -8.666 \\
\hline & $(2.46)^{* *}$ & $(0.86)$ & $(2.75)^{* * *}$ & $(6.48)^{* * *}$ \\
\hline \multirow{2}{*}{$\begin{array}{l}\text { 6. Transfer from village school to county } \\
\text { school, } 1=\text { yes }\end{array}$} & 15.182 & 8.451 & 10.203 & -0.991 \\
\hline & $(8.67)^{* * *}$ & $(4.19)^{* * *}$ & $(5.07)^{* * *}$ & $(0.46)$ \\
\hline \multirow{2}{*}{$\begin{array}{l}\text { 7. Transfer from town school to village } \\
\text { school, } 1=\text { yes }\end{array}$} & 3.032 & -2.244 & -0.492 & -11.686 \\
\hline & $(1.23)$ & $(0.81)$ & $(0.18)$ & $(4.00) * * *$ \\
\hline \multirow{2}{*}{$\begin{array}{l}\text { 8. Transfer from town school to town } \\
\text { school, } 1=\text { yes }\end{array}$} & 3.694 & -0.374 & 1.379 & -9.816 \\
\hline & $(1.98)^{* *}$ & $(0.24)$ & $(0.90)$ & $(5.59)^{* * *}$ \\
\hline \multirow{2}{*}{$\begin{array}{l}\text { 9. Transfer from town school to county } \\
\text { school, } 1=\text { yes }\end{array}$} & 16.028 & 12.731 & 14.484 & 3.290 \\
\hline & $(8.41)^{* * *}$ & $(7.33)^{* * *}$ & $(8.39)^{* * *}$ & $(1.80)^{*}$ \\
\hline \multirow{2}{*}{$\begin{array}{l}\text { 10. Transfer from county school to } \\
\text { village school, } 1=\text { yes }\end{array}$} & -4.837 & -10.979 & -9.226 & -20.420 \\
\hline & $(0.95)$ & $(2.50)^{* *}$ & $(2.11)^{* *}$ & $(4.64)^{* * *}$ \\
\hline \multirow{2}{*}{$\begin{array}{l}\text { 11. Transfer from county school to town } \\
\text { school, } 1=\text { yes }\end{array}$} & 8.345 & -1.171 & 0.582 & -10.612 \\
\hline & $(1.91)^{*}$ & $(0.29)$ & $(0.14)$ & $(2.61)^{* * *}$ \\
\hline \multirow{2}{*}{$\begin{array}{l}\text { 12. Transfer from county school to } \\
\text { county school, } 1=\text { yes }\end{array}$} & 20.595 & 17.114 & 18.867 & 7.673 \\
\hline & $(5.43)^{* * *}$ & $(3.62)^{* * *}$ & $(4.00)^{* * *}$ & $(1.62)$ \\
\hline \multirow[t]{2}{*}{ 13.Study in the same village school } & & & 1.753 & -9.442 \\
\hline & & & $(2.72)^{* * *}$ & $(7.99)^{* * *}$ \\
\hline \multirow[t]{2}{*}{ 14. Study in the same town school } & 0.427 & -1.753 & & -11.194 \\
\hline & $(0.70)$ & $(2.72)^{* * *}$ & & $(9.86)^{* * *}$ \\
\hline \multirow[t]{2}{*}{ 15.Study in the same county school } & 14.321 & 9.442 & 11.194 & \\
\hline & $(17.32)^{* * *}$ & $(7.99)^{* * *}$ & $(9.86)^{* * *}$ & \\
\hline \multicolumn{5}{|l|}{ Board Dummy Variable } \\
\hline \multirow{2}{*}{\multicolumn{2}{|c|}{$\begin{array}{l}\text { 16. Boarding status, } 1=\text { boarded in the } \\
\text { ending primary school }\end{array}$}} & -0.208 & -0.208 & -0.208 \\
\hline & & $(0.36)$ & $(0.36)$ & $(0.36)$ \\
\hline \multicolumn{5}{|l|}{ Student characteristics } \\
\hline \multirow[t]{2}{*}{ 17. Boy $=1$} & & 1.624 & 1.624 & 1.624 \\
\hline & & $(3.50)^{* * *}$ & $(3.50)^{* * *}$ & $(3.50)^{* * *}$ \\
\hline 18. Age, year & & -3.476 & -3.476 & -3.476 \\
\hline
\end{tabular}


19. Hukou identity, $1=$ rural

20. Kindergarten, $1=$ attended

21.Having no sibling, $1=$ yes

22. Grade dummy, $1=$ grade 8

\section{Parental characteristics}

23. Age of father, year

24. Age of mother, year

25. Father holding middle school diploma or above, $1=$ yes

26. Mother holding middle school

27. Father working in agriculture, $1=$ yes

28. Mother working in agriculture, $1=$ yes diploma or above, $1=$ yes

$\begin{array}{ccc}(13.47)^{* * *} & (13.47)^{* * *} & (13.47)^{* * *} \\ -0.286 & -0.286 & -0.286 \\ (0.47) & (0.47) & (0.47) \\ -1.179 & -1.179 & -1.179 \\ (1.40) & (1.40) & (1.40) \\ -0.326 & -0.326 & -0.326 \\ (0.49) & (0.49) & (0.49) \\ 6.727 & 6.727 & 6.727 \\ (13.26)^{* * *} & (13.26)^{* * *} & (13.26)^{* * *}\end{array}$

$\begin{array}{ccc}-0.086 & -0.086 & -0.086 \\ (1.15) & (1.15) & (1.15) \\ 0.056 & 0.056 & 0.056 \\ (0.71) & (0.71) & (0.71) \\ 1.310 & 1.310 & 1.310 \\ (2.37)^{* *} & (2.37)^{* *} & (2.37)^{* *} \\ 0.758 & 0.758 & 0.758 \\ (1.13) & (1.13) & (1.13) \\ -0.931 & -0.931 & -0.931 \\ (1.77)^{*} & (1.77)^{*} & (1.77)^{*} \\ 0.870 & 0.870 & 0.870\end{array}$

(1.63)

(1.63)

\section{Household characteristics}

29. Household size

30. Poor dummy, $1=y e s$

31.Shiquan County, $1=$ yes

32.Hanyin County, 1=yes

Constant (not reported)

Observations

$-0.418$

$(1.73)^{*}$

$-0.418$

$-0.418$

$-0.619$

$(1.73)^{*}$

$(1.73) *$

(1.24)

$-0.619$

$-0.619$

6.306

(1.24)

(1.24)

6.306

6.306

$(9.42)^{* * *}$

$(9.42) * * *$

$(9.42) * * *$

$-4.918$

$(7.58)^{* * *}$

$-4.918$

$-4.918$

$(7.58) * * *$

$(7.58) * * *$

4850

0.20

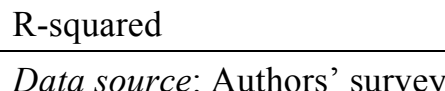

Note:

a. $t$ statistics in parentheses; $*$ significant at $10 \% ; * *$ significant at $5 \% ; * * *$ significant at $1 \%$.

b. The comparison group in model (1) and (2) is the students who studied in the same village school throughout the primary school.

c. The comparison group in model (3) is the students who studied in the same town school throughout the primary school.

d. The comparison group in model (4) is the students who studied in the same county school throughout the primary school. 
Table 5 Covariate Matching results analyzing the effect of transfer path and boarding status on student educational performance (Shaanxi Province, China 2009) $)^{\text {ab }}$

Average treatment effect on the treated (ATT)

(1)

(2)

(3)

(4)

\begin{tabular}{|c|c|c|c|}
\hline Panel A & \multicolumn{3}{|c|}{ The effect of attending the primary school in a county school } \\
\hline Students in the same & Students in the same & Village-county school & $\begin{array}{c}\text { Town-county school } \\
\text { students }\end{array}$ \\
\hline vS. & ys. & vs & vs. \\
\hline $\begin{array}{l}\text { vi. } \\
\text { Students in the same }\end{array}$ & Students in the same & Village (home)-village & Town(home)-town \\
\hline $\begin{array}{l}\text { Students in the same } \\
\text { village school }\end{array}$ & $\begin{array}{l}\text { Students in the same } \\
\text { town school }\end{array}$ & $\begin{array}{l}\text { (awllage (home) - village } \\
\text { (away) school students }\end{array}$ & $\begin{array}{c}\text { (away) school } \\
\text { students }\end{array}$ \\
\hline 14.57 & 7.58 & 11.84 & 8.98 \\
\hline$(4.79) * * *$ & $(3.55) * * *$ & $(3.52) * * *$ & $(3.33) * * *$ \\
\hline \multicolumn{4}{|l|}{ Panel B } \\
\hline \multirow{2}{*}{$\begin{array}{l}\text { Students in the same } \\
\text { town school }\end{array}$} & Village-town school & & \\
\hline & students & & \\
\hline town school & vs. & & \\
\hline \multirow{3}{*}{$\begin{array}{l}\text { Students in the same } \\
\text { village school }\end{array}$} & Village (home) & & \\
\hline & -village (away) & & \\
\hline & school students & & \\
\hline & 1.51 & & \\
\hline$(2.16) * *$ & $(0.86)$ & & \\
\hline \multicolumn{4}{|c|}{ Panel C The pure disruption effect of transfer } \\
\hline \multirow{6}{*}{$\begin{array}{c}\text { Village (home) - village } \\
\text { (away) school students } \\
\text { vs. } \\
\text { Students in the same } \\
\text { village school }\end{array}$} & \multirow{6}{*}{$\begin{array}{l}\text { Town(home) -town } \\
\text { (away) school } \\
\text { students } \\
\text { vs. } \\
\text { Students in the same } \\
\text { town school }\end{array}$} & & \\
\hline & & County(home) - county & \\
\hline & & (av & \\
\hline & & $\begin{array}{l}\text { VS. } \\
\text { Students in the }\end{array}$ & \\
\hline & & Students in the same & \\
\hline & & County schoor & \\
\hline-0.65 & 0.65 & 6.65 & \\
\hline$(0.43)$ & $(0.31)$ & $(1.36)$ & \\
\hline
\end{tabular}

Panel D The effect of starting the primary education in a teaching point

Teaching point-village Teaching point-town

school students school students

VS. VS.

Students in the same Students in the same

village school

town school

$1.42 \quad 5.64$




\begin{tabular}{ccc}
\hline & Panel E & The effect of boarding at school \\
\hline & Boarding students & Boarding students who \\
who studied in the & studied in the same town \\
some village schools & schools \\
vs. & vs. \\
vs. & Non-Boarding & Non-Boarding students \\
Non-boarding students & students who studied & who studied in the same \\
& in the same village & town schools \\
& schools & -0.55 \\
\hline-2.13 & -3.32 & $(0.43)$ \\
\hline
\end{tabular}

Data source: Authors' survey

Note:

a. $\mathrm{z}$ statistics are reported in parentheses; $*$ significant at $10 \% ; * *$ significant at $5 \% ; * * *$ significant at $1 \%$, and nearest neighbor matching was used in matching.

b. In each model, the treatment group is students before the term of "vs." and the comparison group is students after "vs." For example, in mode (1) in Panel A, the treatment group is students who studied in the same county school for all six years throughout their primary school and the comparison group is students who studied in the same village school for all six years throughout their primary school. 


\section{Endnotes}

i In 1994, China's government launched a poverty-reduction initiative under the "8-7 Plan" and designated 592 counties as national designated poor counties. Provinces followed with their own initiatives.

ii Of course, it is possible that there still is a negative disruption effect, but, that the gain is test scores is due to some sort of selection effect (that is, better students- that have higher test scores-were the ones that sought to move from poorer schools to better schools) and that this selection effect was high enough to more than offset any disruption effect.

iii In later analysis, the boarding dummy variable equals to 1 if the student boarded at the school where he/she finished primary education, and it equals to 0 if the student didn't board at the school where he/she finished primary education. We also tried defining boarding status as the boarding dummy variable equals to 1 if the student ever boarded in primary school and it equals to 0 if he/she never boarded. The results are more or less the same.

iv The joint test of coefficients of village-village school transfer dummy and village-county school transfer dummy shows that the two coefficients are significantly different from each other at $1 \%$ level. And, the joint test of the coefficient of village-town school transfer dummy and the coefficient of village-county school transfer dummy shows that the two coefficients are significantly different from each other at $1 \%$ level.

${ }^{v}$ The joint test of coefficients of town-town school transfer dummy and town-county school transfer dummy shows that the two coefficients are significantly different from each other at $1 \%$ level.

${ }^{\mathrm{vi}}$ It should be pointed out that the results do not fully hold for students who started primary education in teaching points. Although students transferring from teaching points to county schools score 3.5 points (5.8-2.3 - column 2, row 3 and 1) and 2.7 points (5.8-3.1 - column 2, row 3 and 2) higher than students transferring from teaching points to village or town schools, the joint test of the coefficients shows that they are not significantly different from each other. Specifically, the joint test of coefficients of teaching point-village school transfer dummy variable and teaching point-county school transfer dummy variable shows that the two coefficients are not significantly different from each other. And the joint test of coefficients of teaching point-town school transfer dummy variable and teaching point-county school transfer dummy variable also shows that these two coefficients are not significantly different from each other.

vii The joint test of coefficients of teaching point-village school transfer dummy variable and village-village school transfer dummy variable shows that the two coefficients are significantly different from each other at $10 \%$ level.

viii The joint test of coefficients of teaching point-town school transfer dummy variable and town-town school transfer dummy variable shows that the two coefficients are significantly different from each other at 5\% level. 